\title{
DE SVANTE ARRHENIUS AO PEAGÂMETRO DIGITAL: 100 ANOS DE MEDIDA DE ACIDEZ
}

\author{
Michelle da Silva Gama e Júlio Carlos Afonso* \\ Departamento de Química Analítica, Instituto de Química, Universidade Federal do Rio de Janeiro, CT, Bloco A, CP 68563,
} 21949-900 Rio de Janeiro - RJ, Brasil

Recebido em 6/4/05; aceito em 13/1/06; publicado na web em 11/8/06

\begin{abstract}
FROM SVANTE ARRHENIUS TO THE DIGITAL pH METER: A CENTURY OF ACIDITY MEASUREMENT. This work describes the establishment of the concept of $\mathrm{pH}$ and the evolution of its measurement. The origin of the $\mathrm{pH}$ definition can be found in the development of the chemistry of aqueous solutions during the XIXth century. The electrolytic dissociation theory by Svante Arrhenius played a central role. After the proposal of the $\mathrm{pH}$ scale by Sörensen, many years were necessary for the acceptance of this new parameter among chemists in general. Its importance was first recognized in biochemistry and related areas. Twenty years after, its importance had been recognized in many industrial and laboratorial practices. The previous methods were based on colorimetric and electrometric methods, but both suffered from many problems. Acceptance of $\mathrm{pH}$ in Chemistry was only possible after the development of experimental trustable measurements. The invention of the $\mathrm{pH}$ meter was the primordial step.
\end{abstract}

Keywords: pH; pH meter; acidity measurement.

\section{O CONHECIMENTO DA QUÍMICA EM SOLUÇÃO AQUOSA NA SEGUNDA METADE DO SÉCULO XIX}

Na segunda metade do século XIX, muitos conceitos físicoquímicos estavam sendo estabelecidos ${ }^{1-5}$. Na década de 1860 , Cato M. Guldberg (1836-1902) e Peter Waage (1833-1900) formularam a lei da ação das massas. Em 1877, Wilhelm Pfeffer (1845-1920) produziu a primeira membrana semipermeável, com a qual descobriu a proporcionalidade entre pressão osmótica e concentração da solução. François-Marie Raoult (1830-1901) publicou em 1883 seus estudos sobre abaixamento do ponto de congelamento e elevação do ponto de ebulição. Esse trabalho serviu de base para os trabalhos de Jacobus H. Van't Hoff (1852-1911) na sua lei de solução diluída, em 1886. Entretanto, as soluções de sais inorgânicos não obedeciam a essa lei e Van't Hoff introduziu o fator de correção $i$ (chamado coeficiente de Van't Hoff, que indica o número médio de partículas formadas por molécula. Ele é associado ao grau de dissociação da mesma ${ }^{6}$ ). Até aquele momento não havia nenhuma explicação para este fato.

Nessa mesma época, uma outra frente de estudos a respeito da pilha voltaica e descobertas relacionadas se estabeleceu. O conceito de ín foi introduzido por Michael Faraday (1791-1867), em 1833, a partir de seus estudos de eletrólise ${ }^{1,4,5}$. Em 1853, Johann W. Hittorf (1824-1914) descobriu que os íons se moviam sob a ação de uma corrente, e que isso variava de espécie para espécie ${ }^{2,3}$. Em 1876, Friederich W. G. Kohlrausch (1840-1910) desenvolveu um novo método para determinar a condutividade, e com isso estabeleceu a lei da migração independente dos ions ${ }^{1-3}$.

Svante Arrhenius (1859-1927) percebeu em sua teoria de dissociação eletrolítica (1887) que a lei da ação das massas podia ser aplicada às reações iônicas ${ }^{3-5}$. Supôs que algumas das moléculas de um eletrólito eram dissociadas em seus íons que, por serem partículas carregadas, eram passíveis de movimento independente sob ação de um campo elétrico. Assim, calculou a pressão osmótica pela lei de Van't Hoff, elucidando o fator $i$. Além disso, também determinou a constante de dissociação dos ácidos e das bases, rela-

*e-mail: julio@iq.ufrj.br cionando a magnitude dessa dissociação com a força do ácido ou da base. Segundo Arrhenius, ácidos são substâncias que produzem, em solução aquosa, íons hidrogênio; analogamente, bases produzem íons hidroxila em solução.

Com o advento da teoria de Arrehenius e os avanços das medidas elétricas, foi possível determinar a constante de dissociação da água pura, pela aplicação da lei da ação das massas. Foi Wilhelm Ostwald (1853-1932), em 1893, quem primeiro fez essa determinação, empregando uma célula de concentração ${ }^{4}$. No ano seguinte, Friederich Kohlrausch e Adolf Heydweiller (1856-1925) determinaram essa constante utilizando medidas de condutância ${ }^{5}$. Todas essas determinações levaram a valores próximos de $1 \times 10^{-14}$ a $25^{\circ} \mathrm{C}$. Com base no processo de auto-ionização da água:

$\mathrm{H}_{2} \mathrm{O} \rightleftarrows \mathrm{H}^{+}+\mathrm{OH}^{-}$

tem-se, de acordo com a lei da ação das massas:

$\mathrm{K}=\frac{\left[\mathrm{H}^{+}\right]\left[\mathrm{OH}^{-}\right]}{\left[\mathrm{H}_{2} \mathrm{O}\right]}$

Como esse processo ocorre em extensão mínima, a concentração da água no equilíbrio é praticamente igual à concentração inicial, onde:

$\mathrm{K}\left[\mathrm{H}_{2} \mathrm{O}\right]=\mathrm{K}^{\prime}=\left[\mathrm{H}^{+}\right]\left[\mathrm{OH}^{-}\right]$

Ao produto $\left[\mathrm{H}^{+}\right]\left[\mathrm{OH}^{-}\right]$deu-se o nome de produto iônico da água, $\mathrm{Kw}$, etapa importante no estabelecimento posterior do conceito de $\mathrm{pH}$. Naquela época já era conhecido que Kw era dependente da temperatura. Por ex., as medições de Friederich Kohlrausch e Adolf Heydweiller, em $1894^{5,7}$, davam para Kw, a 10 e a $60{ }^{\circ} \mathrm{C}$, os valores respectivos de $0,31 \times 10^{-14}$ e $11,04 \times 10^{-14}$. O estabelecimento do conceito de $\mathrm{Kw}$ referia-se à água pura apenas, mas já se percebia naquele tempo que a dissolução de sais derivados de ácidos e bases fortes não perturbava o equilíbrio iônico da água, pela ausência de fenômenos de hidrólise dos íons adicionados a ela $a^{1,3,6,7}$. 


\section{A IMPORTÂNCIA DO ÍON HIDROGÊNIO NOS SISTEMAS BIOLÓGICOS}

Por volta de 1900, muitas equações matemáticas utilizadas para expressar equilíbrio químico, concentração de $\mathrm{H}^{+}$, etc já haviam sido elaboradas. Para os químicos da época, a determinação da concentração do íon hidrogênio era uma questão de interesse puramente teórico, mas para biólogos e bioquímicos a situação era muito diferente $\mathrm{e}^{4-5}$. Por trabalharem com organismos vivos, lidavam constantemente com os sistemas de tampões naturais e, por conseguinte, com o desafio de determinar a concentração do íon $\mathrm{H}^{+}$, fator crítico nesse sistema.

Em 1900 Auguste Fernbach (1860-1939) e L. Hubert (18651943), pesquisadores franceses, perceberam que o extrato de malte apresentava a propriedade de não variar sua atividade enzimática quando se adicionavam pequenas quantidades de um ácido ou de uma base. Eles então concluíram que o malte, assim como muitos fluidos naturais, compartilhava a propriedade de resistir a mudanças abruptas de acidez ou de alcalinidade. Foram os primeiros a utilizar a palavra tampão para explicar esse fenômeno ${ }^{1,4,5}$.

Por volta de 1903, o fisiologista húngaro Pal Szily (1878-1945) constatou que o soro sanguíneo possuía propriedades tamponantes; através de seus estudos definiu os limites em que ocorriam as reações no soro, na faixa de concentração de íon hidrogênio $\left[\mathrm{H}^{+}\right]$entre $1 \times 10^{-4}$ e $2 \times 10^{-10} \mathrm{~mol} \mathrm{~L}^{-1}$. Sob orientação de Hans Friedenthal (18701943), Slizy trabalhou na determinação da concentração do íon hidrogênio utilizando métodos colorimétricos ${ }^{1,2,4,5}$.

Em 1875 Louis Pasteur (1822-1895), em seus estudos de fermentação, foi o primeiro a reconhecer que a acidez real é bem diferente da acidez total, pois ácidos com mesmo número de hidrogênios ionizáveis não têm necessariamente a mesma força. Daí surgiu a necessidade de medir e exprimir essa acidez em solução, pois se tratava de uma variável importante nos procedimentos biológicos e bioquímicos em geral $^{3,8,9}$. Isso significa que a importância e a necessidade de quantificar a acidez se estabeleceram antes do advento do pH. Contudo, antes de Sörensen, era raro um trabalho que relacionasse o andamento de uma reação química e a acidez do meio 9 .

\section{A INVENÇÃO DA ESCALA DO pH E SUA ABRANGÊNCIA}

Em 1904, Hans Friedenthal ${ }^{10}$ recomendou a utilização da concentração do íon hidrogênio para caracterizar soluções, e também sugeriu que as soluções alcalinas poderiam ser caracterizadas, em termos de concentração do íon hidrogênio, desde que fossem sempre iguais a $1 \times 10^{-14} / \mathrm{C}_{\mathrm{H}}^{+}$, isto é, $\left[\mathrm{H}^{+}\right] \times\left[\mathrm{OH}^{-}\right]=10^{-14}$. Naquela época, na área de ácido-basicidade e de tampões, os gráficos de neutralização eram apresentados tendo como uma das variáveis a concentração do íon hidrogênio $\left[\mathrm{H}^{+}\right]$ou o $\log \left[\mathrm{H}^{+}\right]$, sem aplicação da definição de Sörensen ${ }^{5,7,9}$. Para contornar o uso de muitos zeros trabalhava-se com notação científica e, quando da aplicação do logaritmo, com números negativos ${ }^{7,8}$.

Em 1909 Sören P. T. Sörensen (1868-1939), bioquímico dinamarquês, estabeleceu uma maneira conveniente de expressar a acidez utilizando o logaritmo negativo da concentração do íon hidrogênio: $\mathrm{pH}=-\log \left[\mathrm{H}^{+}\right]$. Ele chamou de expoente do íon hidrogênio representado pelo símbolo $\mathrm{pH}$ "pondus hidrogenni - potencial de hidrogênio". Devido ao uso do artifício matemático "- $\log \left[\mathrm{H}^{+}\right]$" os valores dessa escala são positivos na faixa de concentração abaixo de $1 \mathrm{~mol} \mathrm{~L}^{-1}$. A rigor, o $\mathrm{pH}$ é mais bem definido como sendo $\mathrm{pH}=$ $-\log \mathrm{a}_{\mathrm{h}}$, onde $\mathrm{a}_{\mathrm{h}}$ é a atividade do íon hidrogênio ${ }^{11,12}$. Em soluções contendo mais de um íon a atividade e a concentração são diferentes, porque a atividade é a concentração real de um eletrólito em solução. Ela é função de todos os componentes iônicos em solução (força iônica), ou seja, em soluções concentradas é o produto da molaridade pela força iônica. Na prática, a definição original de Sörensen ainda pode ser utilizada porque os instrumentos empregados para fazer a medição podem ser calibrados com soluções de concentração de íon hidrogênio conhecida ${ }^{3,6,12}$.

$\mathrm{O}$ conceito de $\mathrm{pH}$, a rigor, só se aplica a soluções aquosas e tanto mais diluídas estas forem. Caso se necessitasse calcular a basicidade de um meio ( $\mathrm{pOH})$, utilizava-se a expressão $\mathrm{pH}+\mathrm{pOH}$ $=14$. Por isso, a importância do produto iônico da água $(\mathrm{Kw})$ no estabelecimento do $\mathrm{pH}$. Isso também ilustra que os valores da escala de $\mathrm{pH}$ não são arbitrários, mas se originam da medida experimental do Kw. Como este varia com a temperatura, a escala de $\mathrm{pH}$ também variará. Por ex., na temperatura do corpo humano $\left(37^{\circ} \mathrm{C}\right)$, $\mathrm{pH}+\mathrm{pOH}=13,6$ e o pH referente à neutralidade é de $6,8^{11}$.

Apesar do conceito de $\mathrm{pH}$ como " $-\log \left[\mathrm{H}^{+}\right]$" ser exclusivamente creditado a Sörensen, os trabalhos de Friedenthal de determinação da concentração do íon hidrogênio forneceram o subsídio fundamental para o estabelecimento do artifício logarítmico. Seria mais justo, pois, creditar a ambos o mérito da introdução do conceito de $\mathrm{pH}$; muitos autores mesmo opinam que Friedenthal foi o real introdutor dessa escala ${ }^{5,13}$.

Até Sörensen propor a escala de $\mathrm{pH}$, não havia uma forma amplamente aceita de expressar a concentração do íon hidrogênio $^{7,8,11}$. O emprego do conceito de $\mathrm{pH}$ espalhou-se rapidamente entre bioquímicos e enzimologistas, que o utilizaram em estudos de ação tamponante dos tecidos vivos ${ }^{14}$. Por outro lado, muitos químicos foram vagarosos, e mesmo reticentes, em aceitar esse novo conceito ${ }^{1,4,8,14-16}$. Um exemplo desse ceticismo com que foi tratado o pH está no texto a seguir: "Para físicos e químicos, a noção de pH não provocou grande entusiasmo; o mesmo não sucedeu na biologia e na medicina, que se perderam na filosofia e na poesia, sem se deter no rigor científico, o que explica o porquê de tantos trabalhos sobre $\mathrm{pH}$ devidos a eles (...). O $\mathrm{pH}$, isoladamente, significa coisa alguma ou quase nada" ${ }^{15}$. É interessante notar que as questões de ordem prática relativas à concentração do íon hidrogênio não figuravam nos assuntos de interesse dos químicos da época. Isso fica mais evidente quando se constata que boa parte dos conceitos, das medições e teorias elaboradas sobre o assunto foram formuladas, defendidas e publicadas por bioquímicos, biólogos e profissionais de áreas afins.

\section{A DIFUSÃO DO pH NO MUNDO CIENTÍFICO}

A escala de $\mathrm{pH}$, apesar de cômoda e hoje usual, não foi aceita de imediato entre os químicos, sofrendo duras críticas. O primeiro livro de Química que menciona o conceito de $\mathrm{pH}$ foi publicado em $1914^{4}$, cinco anos após a proposição de Sörensen, sob o título Die Wasserstoffionenkonzentration, sendo escrito por Leonor Michaelis (1875-1950), professora de Química Médica em Berlim. No prefácio de seu livro, ela lamenta a falta de interesse dos químicos pelo assunto. Em 1920, William M. Clark (1884-1964) publicou o livro The Determination of Hydrogen Ions, de grande repercussão na época, pois introduziu a dosagem eletrométrica com vistas a obter medidas mais precisas ${ }^{4,5}$. Esse livro foi o primeiro de uma série publicada ao longo de 20 anos sobre o íon hidrogênio. Na década de 1920, a literatura registra algo em torno de 10.000 trabalhos $^{16}$ neste campo, o que comprova quão importante se tornou esse assunto na época.

No Brasil, o pH começou a figurar em livros de Química em meados dos anos 1920. Contudo, a título de ilustração, as obras Pontos de Chimica ${ }^{17}$, de 1928, e Noções Rudimentares de Química Analítica e Quantitativa ${ }^{18}$, de 1932, editadas no Brasil, limitavamse a uma descrição muito sucinta da definição de $\mathrm{pH}$ e da 
metodologia de determinação; a ênfase recaía no cálculo puro e simples, em detrimento do significado do conceito em questão.

Foram encontrados livros-texto editados ao final dos anos 1920 em que ainda se usava a expressão $\left[\mathrm{H}^{+}\right]\left[\mathrm{OH}^{-}\right]=1 \times 10^{-14}$ (a proposta de H. Friendenthal, de 1904) para traçar as curvas de titulação ácido-base ${ }^{19}$. Apesar da grande quantidade de trabalhos publicados naquela época, o conceito de $\mathrm{pH}$ proposto por Sörensen não estava totalmente consolidado.

\section{A IMPOSIÇÃO DO pH COMO MEIO DE AVALIAÇÃO DA ACIDEZ}

Na década de 1920, houve uma grande discussão sobre a real utilidade da notação de Sörensen e várias escalas foram propostas para substituí-la.

O emprego do conceito de $\mathrm{pH}$ tinha a vantagem de evitar cálculos com número muito pequenos, cheios de zeros à esquerda, ou a manipulação de números negativos, facilitando a construção de gráficos e reduzindo as possibilidades de erro de cálculo ${ }^{7-9,20-22}$.

Os inconvenientes da escala de Sörensen que geravam reclamações eram ${ }^{1,4,5,8,9,13,15,20-22}$ : o problema de a acidez decrescer quando o $\mathrm{pH}$ subia e vice-versa; a falta de uma marca que caracterizasse a passagem de acidez à alcalinidade; a variação de acidez não correspondia à do $\mathrm{pH}$, ou seja, uma unidade logaritmica significava uma variação de 10 vezes a acidez do meio; não havia uma maneira uniforme de representar a escala de Sorensen: fora a maneira hoje consagrada de representar como $\mathrm{pH}$, ainda se escrevia $\mathrm{PH}, \mathrm{Ph}, \mathrm{p}_{\mathrm{H}}, \mathrm{P}_{\mathrm{H}}$, conforme o país onde se originava o trabalho. Se a concentração do íon hidrogênio fosse maior que $1 \mathrm{~mol} \mathrm{~L}^{-1}$, o pH, pela sua definição, seria um valor negativo, mais um fator a confundir a mente do operador ou do aluno ${ }^{23}$. Além disso, quanto menor o grau de dissociação de um ácido ou de uma base, menor a variação do $\mathrm{pH}$ de sua solução aquosa em função da concentração desse soluto ${ }^{8,9,15}$. Por tudo isso diversas outras escalas de acidez foram propostas, como se vê na Tabela $1^{9,15,24-28}$.

A proposta de Wherry foi duramente criticada por William M. Clark e por Izaak M. Kolthoff (1894-1993), que a consideravam "bizarra e tratava-se apenas de uma outra forma não linear de relacionar a acidez com a escala proposta" 29,30 . Ambos também acreditavam que não havia nenhuma razão para se dar um significado especial à neutralidade pois, a rigor, somente a água pura e soluções diluídas de sais derivados de ácido e base fortes tinham pH 7. As escalas de Blackaddor e Guillaumin eram restritas a casos especiais, que não se prestavam para uso prático geral. A escala de Giribaldo, proposta em $1925^{27,28}$, foi a alternativa mais comentada no meio científico da época, sendo muito atrativa devido à simplicidade de sua definição e à capacidade de distinguir a faixa alcalina da ácida (Tabela 1). A despeito do nítido apoio de pesquisadores russos e italianos ${ }^{4.59 .15}$, a escala de Giribaldo não se consagrou $^{23,29-31}$. A partir da fórmula apresentada na Tabela 1 e da expressão $\left[\mathrm{H}^{+}\right]\left[\mathrm{OH}^{-}\right]=1 \times 10^{-14}$, pôde-se demonstrar que os valores de $\mathrm{P}_{\mathrm{R}}$ não variavam com o logaritmo da concentração do íon hidrogênio, mas sim com o logaritmo do quadrado dessa concentração $\left(P_{R}=14\right.$ $\left.+2 \log \left[\mathrm{H}^{+}\right]\right)$, o que amplificava o erro desse parâmetro no caso de medida incorreta de acidez. Apesar de Giribaldo afirmar ${ }^{27,28}$ que sua escala era insensível à temperatura (ao contrário do que sucede com o $\mathrm{pH}$ ), o quociente $\left[\mathrm{H}^{+}\right] /\left[\mathrm{OH}^{-}\right]$é sensível às variações de $\mathrm{Kw}$ com a temperatura, exceto unicamente no caso da neutralidade.

Diversas outras tentativas de se criar uma escala alternativa àquela proposta por Sörensen apresentavam fórmulas de cálculo mais complexas que a do $\mathrm{pH}$, o que levou ao abandono dessas propostas pela não praticidade no uso rotineiro ${ }^{23}$.

A dificuldade do conceito de $\mathrm{pH}$ se estabelecer entre os químicos talvez se explique, ao menos em parte, por outro ângulo ${ }^{32}$ : na década de 1920, a teoria de Arrhenius, sob a qual se insere o conceito de $\mathrm{pH}$, sofria duras críticas por conta de suas limitações à vista do progresso que a Química experimentava até então. As teorias protônicas (Brönsted-Lowry) e eletrônica (Lewis) foram propostas para resolver as lacunas que a teoria de Arrhenius não explicava. Para estas novas teorias o conceito de $\mathrm{pH}$ era irrelevante, e casos onde o $\mathrm{pH}$ tinha aplicabilidade duvidosa (caso de meios ácidos e básicos concentrados, reações em sistemas sólidos, etc) passaram a ter um tratamento conceitual.

$\mathrm{O}$ conceito de $\mathrm{pH}$ foi bem acolhido nos Estados Unidos, era considerado um meio conveniente de expressar a acidez de soluções de ácidos/bases e de caracterizar produtos industriais e fisiológicos $^{9}$. $\mathrm{Na}$ área de ensino ${ }^{8}$, em razão da freqüência com a qual se empregava a expressão "pH" unicamente como ferramenta de cálculo algébrico, foi necessária a publicação de obras que visassem esclarecer esse novo parâmetro físico-químico. H. Chakmakjiam, professor da Escola de Medicina de Boston e membro da "Division of Chemical Education" da "American Chemical Society" defendeu em reunião daquela divisão: "A questão é que a redução do conceito a uma mera operação matemática incomodava, pois os alunos aprendiam $\mathrm{pH}$ sem relacioná-lo aos fenômenos físico-químicos pertinentes. Era necessária a junção de conceitos termodinâmicos e eletroquímicos para dar uma melhor visão do que ocorre nas soluções iônicas, dispersando a aura de mistério que cerca a mente do aluno" ${ }^{31}$. No início dos anos 1960, a idéia da acidez crescer com o abaixamento do $\mathrm{pH}$, e vice-versa, era ainda uma dificuldade apontada pelos alunos no ensino americano ${ }^{23}$.

A introdução do $\mathrm{pH}$ como ferramenta de controle revolucionou inúmeros processos industriais em meio aquoso: precipitações, culturas bacteriológicas, produção de vacinas, galvanoplastias, fermenta-

Tabela 1. Escalas alternativas à definição de pH proposta por Sörensen

\begin{tabular}{|c|c|c|}
\hline Escala & Descrição & Comentários \\
\hline Blackaddor $^{24}$ & $\begin{array}{l}\text { pH: } 4,8 \text { - acidez potencial }=0 \text { (ponto isoelétrico da } \\
\text { gelatina), variação logaritmica em torno deste ponto }\end{array}$ & $\begin{array}{l}\text { Adequada para segmentos das indústrias bioquímica, } \\
\text { fotográfica e alimentícia }\end{array}$ \\
\hline Guillaumin $^{25}$ & Divisão do segmento $\mathrm{pH}$ 6,77-7,60 em 200 partes & Destinada a estudos fisiológicos e bioquímicos \\
\hline Wherry $^{26}$ & $\begin{array}{l}\text { Em } \mathrm{pH}=7 \text { atribuir "acidez ativa" }=1 \\
\text { pH }=6, \text { acidez ativa } 10 ; \\
\text { pH }=5, \text { acidez ativa }=100 \text { e assim por diante; } \\
\text { pH }=8, \text { alcalinidade ativa }=10 ; \\
\text { pH }=9, \text { alcalinidade ativa }=100 \text { e assim por diante }\end{array}$ & $\begin{array}{l}\text { Grau de acidez e alcalinidade é descrito como mínimo, } \\
\text { submédio e super (termo superácido aparece pela } \\
\text { primeira vez na literatura) }\end{array}$ \\
\hline Giribaldo $^{27,28}$ & $\begin{array}{l}\text { Cálculo da razão } \mathrm{R}=\left[\mathrm{H}^{+}\right] /\left[\mathrm{OH}^{+}\right] \\
\log \mathrm{R}=\mathrm{P}_{\mathrm{R}}=\log \left[\mathrm{H}^{+}\right] /\left[\mathrm{OH}^{+}\right]\end{array}$ & $\begin{array}{l}\text { Em pH } 7 \text { o valor de } \mathrm{P}_{\mathrm{R}} \text { é zero; assume valores positivos } \\
\text { na faixa ácida e negativos na faixa alcalina }\end{array}$ \\
\hline
\end{tabular}


ções, produção de leite e derivados, curtição de couro, etc e, também, diversas operações unitárias da indústria (filtração, decantação, flotação), feitas antes às custas de procedimentos inadequados, tanto do ponto de vista dos processos quanto da saúde do operador ${ }^{8,9,33,34}$ : permanência por longo período na área de produção sem equipamentos de proteção adequados; manipulação de grandes volumes de amostras; lentidão na obtenção dos resultados (o que aumentava o risco de acidentes, devido à demora em corrigir alguma variável de processo). Os exemplos acima e muitos outros mostram que, mesmo antes do estabelecimento de metodologias confiáveis e definitivamente reprodutíveis, o $\mathrm{pH}$ assumiu importância fundamental no segmento industrial ${ }^{8,9.20 .31,33,34}$, situação válida até hoje. Contudo, houve relatos de emprego sem critério do $\mathrm{pH}$, levando a situações inusitadas, como atestam os seguintes exemplos ${ }^{8,33}$ : ajuste do $\mathrm{pH}$ de um meio fermentativo sem que a temperatura do mesmo estivesse na faixa adequada à cultura microbiana; neutralização de soluções a $80-90^{\circ} \mathrm{C}$ afirmando que o pH era 7; regular a "acidez" de soluções onde o solvente não era água pura e sim, misturas de solventes (água + álcool, por ex.). Esses casos mostraram que o $\mathrm{pH}$ não podia ser o único parâmetro de controle, devendo ser associado a outros itens de monitoramento do processo (temperatura, composição do meio, vazão, etc). Isso também justificou a publicação naquela época de obras esclarecedoras sobre o pH para clientela não-química (farmacêuticos, engenheiros, geólogos, agrônomos, técnicos, etc), para que esses profissionais tirassem o máximo proveito desse conceito em seus trabalhos. Isso se revelou um exemplo de cooperação entre indústria e academia ${ }^{8,31,33}$.

\section{DETERMINAÇÃO DO pH}

Os métodos disponíveis para determinação do pH são fundamentalmente colorimétricos e eletrométricos. Apesar destes últimos serem utilizados quase que exclusivamente hoje em dia, os métodos colorimétricos foram favorecidos por muitos anos devido à falta de conhecimentos técnicos que pudessem fazer dos métodos eletrométricos algo rotineiro.

\section{Os métodos colorimétricos}

Esses procedimentos foram usados empiricamente durante décadas, embora teorias físico-químicas, hoje, expliquem o princípio dos indicadores utilizados (W. Ostwald, em 1894, foi o primeiro a dar uma explicação do fato). Eles se baseiam na mudança de cor quando certas substâncias entram em contato com meio ácido ou alcalino. Na concepção de Sörensen e Friedenthal, a comparação do pH de uma substância desconhecida era feita contra uma série de soluções preparadas com pH bem delineado (tamponadas) e de coloração característica, chamada escala colorimétrica. Por comparação entre a coloração dos padrões da escala e da amostra chegava-se a um $\mathrm{pH}$ próximo do real. Essa metodologia apresentava erros, tais como a acuidade visual diferenciada de cada um, a viragem de indicador pouco marcante, a influência da temperatura e da concentração das espécies e os efeitos de espécies salinas, oxidantes e redutoras ${ }^{12,13,29,35}$.

Além da comparação a olho nu, também se utilizavam aparelhos conhecidos como comparadores (como o modelo de Walpole), e colorímetros como os de Dubosq ${ }^{24-27}$. Em ambos os casos, fazia-se a comparação ótica das cores da solução em análise e dos padrões de pH conhecidos. Não era qualquer substância corada que mudava de cor com o $\mathrm{pH}$ que poderia ser utilizada como indicador ${ }^{36}$.

As misturas tampão oferecidas no comércio cobriam a faixa de 1 a 13 de $\mathrm{pH}$, com variação interna de até 0,05 unidades. Algumas dessas soluções duravam pouco tempo, o que exigia uma escolha criteriosa do tampão para a faixa que se desejava trabalhar. Em
1915, William M. Clark e Herbert A. Lubs introduziram as sulfoftaleínas ${ }^{37}$, o que aumentou a versatilidade dos métodos colorimétricos (determinação em faixa estreita e maior durabilidade dos indicadores) $)^{5}$. A Tabela 2 ilustra diversos sistemas tampão disponíveis em $1925^{38}$. Cada substância componente da mistura tampão era dosada (por gravimetria, volumetria, titulometria) antes de ser utilizada no preparo dos padrões. Devido à facilidade de preparo e purificação, os indicadores de Clark e Lubs (Tabela 3) foram dos mais utilizados na época ${ }^{34,35,38}$.

Tabela 2. Sistemas-tampão já estabelecidos em 1925

\begin{tabular}{lcc}
\hline Proponente(s) & Ano & Faixa de $\mathrm{pH}$ \\
\hline Sörensen & 1908 & $1,04-12,9$ \\
Clark e Lubs & 1919 & $1,2-10,0$ \\
Mc IIvaine & 1921 & $2,2-8,0$ \\
Walpole & 1910 & $3,8-5,7$ \\
Politsch & 1915 & $6,7-9,24$ \\
Mc Clendon et al. & 1922 & $7,45-9,05$ \\
Kolthoff & 1925 & $10,17-11,36$ \\
Ringer & 1924 & $10,97-12,06$ \\
\hline
\end{tabular}

Tabela 3. Corantes e soluções-tampão propostos por Clark e Lubs (1919)

\begin{tabular}{|c|c|c|}
\hline Indicador & Mudança de cor & $\begin{array}{l}\text { Faixa de } \\
\text { viragem }\end{array}$ \\
\hline Azul de timol & Vermelho-amarelo & $1,2-2,8$ \\
\hline Azul de bromofenol & Amarelo-azul & $3,0-4,6$ \\
\hline Vermelho de metila & Vermelho-amarelo & $4,4-6,0$ \\
\hline Púrpura de bromocresol & Amarelo-púrpura & $5,2-6,8$ \\
\hline Azul de bromotimol & Amarelo-azul & $6,0-7,6$ \\
\hline Vermelho de fenol & Amarelo-vermelho & $6,8-8,4$ \\
\hline Vermelho de cresol & Amarelo-violeta & $7,2-8,8$ \\
\hline Azul de timol & Amarelo-azul & $8,0-9,6$ \\
\hline \multicolumn{3}{|l|}{ Soluções-tampão } \\
\hline \multicolumn{2}{|c|}{$\mathrm{KCl} 0,2 \mathrm{~mol} \mathrm{~L}^{-1}+\mathrm{HCl} 0,2 \mathrm{~mol} \mathrm{~L}^{-1}$} & $1,2-2,2$ \\
\hline \multicolumn{2}{|c|}{$\begin{array}{l}\text { Ftalato ácido de potássio } 0,2 \mathrm{~mol} \mathrm{~L}^{-1}+ \\
\mathrm{HCl} 0,2 \mathrm{~mol} \mathrm{~L}^{-1}\end{array}$} & $2,2-3,8$ \\
\hline \multicolumn{2}{|c|}{$\begin{array}{l}\text { Ftalato ácido de potássio } 0,2 \mathrm{~mol} \mathrm{~L}^{-1}+ \\
\mathrm{NaOH} 0,2 \mathrm{~mol} \mathrm{~L}^{-1}\end{array}$} & $4,0-6,2$ \\
\hline \multicolumn{2}{|c|}{$\mathrm{KH}_{2} \mathrm{PO}_{4} 0,2 \mathrm{~mol} \mathrm{~L}^{-1}+\mathrm{NaOH} 0,2 \mathrm{~mol} \mathrm{~L}^{-1}$} & $5,8-8,0$ \\
\hline \multicolumn{2}{|c|}{$\mathrm{H}_{3} \mathrm{BO}_{3}+\mathrm{KCl}+\mathrm{NaOH} 0,2 \mathrm{~mol} \mathrm{~L}^{-1}$} & $7,8-9,6$ \\
\hline
\end{tabular}

Como critério visual, a mudança da cor da forma ácida para a básica (e vice-versa) ocorre quando a razão entre as concentrações da forma ácida (alcalina) e da alcalina (ácida) for maior que aproximadamente 10. Essa razão pode ser melhor determinada utilizandose um método espectrofotométrico. $\mathrm{O}$ equilíbrio da mudança de cor (em uma dada força iônica) pode ser dado pela Equação 4

$\mathrm{pH}=\mathrm{pK}_{\text {in }}+\log \left[\operatorname{In}_{\mathrm{B}}\right] /\left[\operatorname{In}_{\mathrm{A}}\right]$

onde $\mathrm{pK}_{\text {in }}$ é a chamada constante aparente do indicador. Com base na mudança de cor em função das concentrações das espécies ácida e básica (10/1 ou 1/10), a faixa de viragem da cor do indicador pode ser expressa segundo a Equação 5

$\mathrm{pH}=\mathrm{pK}_{\text {in }} \pm 1$ 
ou seja, a faixa de viragem do indicador corresponde a cerca de duas unidades de $\mathrm{pH}$.

$\mathrm{O}$ primeiro indicador de $\mathrm{pH}$ comercialmente vendido foi o tornassol (litmato de cálcio). O reagente era originalmente sólido e vendido em grãos na cor vermelha (faixa ácida) ou azul (faixa alcalina). Era obtido de diversas fontes, desde liquens até crustáceos. A partir do final dos anos 1920, já havia à venda a tintura de tornassol (lackmus tinktur). A impregnação dessa tintura em papel foi a grande idéia que possibilitou o uso generalizado desse insumo ${ }^{35,39,40}$. Entretanto, outras substâncias conhecidas na época agiam sob uma faixa de $\mathrm{pH}$ mais estreita, conhecida como zona de viragem. A cada momento surgiam novos indicadores capazes de alargar a faixa de $\mathrm{pH}$ passível de ser medida ou de estreitar a determinação a um intervalo cada vez menor.

Em lugares onde não era possível levar aparelhagens (zona rural, jazidas minerais, etc) utilizava-se papel impregnado com indicador para se medir o $\mathrm{pH}$. Este ainda não era o papel indicador universal como é conhecido hoje. Os primeiros papéis surgiram nos anos 1920 a partir de várias pesquisas, particularmente as de Izaak M. Kolthoff ${ }^{34}$. O papel surgiu inicialmente apenas para estimativas grosseiras de $\mathrm{pH}$ onde a rapidez da obtenção do resultado era primordial, daí a pouca receptividade em seus primeiros tempos.

O caminho seguido até o lançamento dos papéis indicadores de pH universal passou pela formulação de kits de soluções contendo vários indicadores de $\mathrm{pH}$ bem delineados e com coloração característica (a escala colorimétrica). A impregnação dos indicadores em papel e o refinamento das misturas dos mesmos permitiram obter os tão conhecidos papéis de $\mathrm{pH}$ universal, bastantes utilizados desde os anos $1950^{40}$. Quando o papel universal entrou em uso, a escala comparativa (colorimetria) perdeu a utilidade ${ }^{31,33,35,39}$. Donald M. Quintela, professor de Química Analítica da Faculdade Nacional de Farmácia da Universidade do Brasil e um dos que difundiu o papel universal no país, reconhecia a sua utilidade no ensino: "Já têm sido propostas e divulgadas diversas fórmulas dos chamados indicadores universais (...) É de grande utilidade prática, em muitos laboratórios, poder estimar a ordem de grandeza do pH em um líquido em exame, dispondo apenas de recursos ordinários do próprio laboratório, isto é, sem concurso de aparelhos especiais, geralmente de preço muito superior ao valor intrínseco" 39 .

A apresentação dos papéis de $\mathrm{pH}$ no mercado não mudou significativamente ao longo do tempo, sendo comercializados sob várias formas (tiras, rolos, blocos, etc). Atualmente, os indicadores são quimicamente imobilizados sob papel ou plástico a fim de evitar a rápida dissolução do corante (sangramento) quando a tira permanece na solução por longos períodos de tempo, problema este bastante comum nas primeiras versões de papéis indicadores utilizados no início da década de $1930^{13}$. O indicador é ligado covalentemente à fibra de celulose, ou copolimerizado com acrilamina e metacrilato $^{13}$

\section{Os métodos eletrométricos de medição de acidez até os anos 1920}

Com o passar dos anos, o pH estabeleceu-se como um dos principais parâmetros de medida em vários segmentos industriais, além de seu uso no meio acadêmico gerando, por isso, uma demanda cada vez maior de medidas de $\mathrm{pH}$ precisas, o que de certa forma, era praticamente impossível com os métodos colorimétricos, apesar destes serem reconhecidos como sendo de utilização mais rápida e cômoda ${ }^{8,9,20,36}$.

A partir de cerca de 1920 os procedimentos eletrométricos (potenciometria, condutimetria, amperometria), os viscosimétricos e o emprego de eletrodos de óxidos metálicos começaram a ganhar espaço $^{13,34,35}$, pois superavam deficiências dos métodos colorimétricos, tais como melhor precisão, existência de soluções sem um bom indicador e determinação de soluções coradas ${ }^{19}$. Apesar de, em 1893, W. Ostwald já ter medido a concentração iônica utilizando medidas condutimétricas e Walter H. Nernst (1864-1941), em 1889, ter estabelecido uma relação matemática entre potencial e concentração iônica, fatores de fórum prático impediam a ampla utilização de métodos eletrométricos. Nos primeiros anos do século XX, a precariedade de equipamentos, a carência de profissionais qualificados para operação dos instrumentos e o alto custo dos mesmos eram sérios entraves à difusão dos métodos eletrométricos de determinação da acidez de uma solução ${ }^{13,20,31,41}$.

As montagens elétricas eram feitas através da união de vários componentes, unidos por fios, ou seja, não havia um instrumento único para determinação da acidez de uma solução ${ }^{31,32}$. Esses esquemas podiam apresentar diversos problemas ${ }^{13,20,42}$ : possibilidade de ligações equivocadas ou de inversões de polaridade que levavam a curto-circuitos e mesmo explosões de eletrodos; dificuldade de ajustar o "zero" - a flutuação excessiva da corrente levava a oscilações que dificultavam medidas reprodutíveis; os fios nem sempre eram verificados quanto à sua integridade física, bem como as soldas e junções nas conexões dos diversos componentes; os eletrodos apresentavam freqüentemente defeitos, especialmente o de hidrogênio (negro de platina oxidado ou não homogêneo), ou seja, a baixa durabilidade do instrumento e sua confiabilidade duvidosa; a temperatura da medida era diferente da do ambiente, sem que se pudessem utilizar fatores de correção no instrumento; o aparecimento do potencial de junção (líquida) entre as células e a dificuldade de controlá-lo, ou, pelo menos, de minimizá-lo.

Um dos componentes obrigatórios dessas montagens era a $p i-$ lha-padrão, que tem a característica de apresentar um potencial constante e independente do $\mathrm{pH}$, prestando-se para comparação entre seu potencial e o do sistema que se deseja medir9,15,34,36. A primeira versão foi proposta em 1872 por Josiah L. Clark (18221898), baseada no sistema $\mathrm{Hg}(\mathrm{Zn}) / \mathrm{ZnSO}_{4}$ saturado. Foi o primeiro modelo reprodutível e de sucesso comercial. Foram introduzidos melhoramentos, culminando em 1892 pela proposta da chamada pilha de Weston (Edward Weston, 1850-1936), que tem um potencial de $+1,0183 \mathrm{~V}$ à $20^{\circ} \mathrm{C}$ (constante até cerca de $40{ }^{\circ} \mathrm{C}$ ), baseada no sistema $\mathrm{Hg}(\mathrm{Cd}) / \mathrm{HgSO}_{4}$. Os modelos tinham em comum a entrada para termômetro, ligação (+)/(-) da conexão elétrica, visor de nível de líquido e entrada de reposição de água.

Uma alternativa à pilha-padrão é o eletrodo de referência (antes chamada pilha de concentração). Em 1893, Max J. L. Le Blanc (18651943) mostrou que um eletrodo de platina platinizada funcionava como um eletrodo reversível de hidrogênio, se este gás fosse borbulhado ao redor do eletrodo. Em 1895, O. F. Tower sugeriu a utilização de uma solução concentrada de cloreto de potássio entre as duas meias células para diminuir o potencial de junção líquida ${ }^{12,13,43}$ (decorrente da diferença de velocidade de migração (mobilidade) entre os íons, em especial os íons $\mathrm{H}^{+}$e $\mathrm{OH}^{-}$, que são mais móveis. Ele aparece entre duas soluções eletrolíticas diferentes, que estão em contato por meio de uma interface). O potencial de junção limita a exatidão da medida porque contribui, com uma parcela desconhecida, para a medida de potencial que aparece entre elas.

Sörensen foi o primeiro a utilizar o eletrodo de calomelano $\left(\mathrm{Hg}_{2} \mathrm{Cl}_{2} / \mathrm{Hg}\right)$ para determinar o $\mathrm{pH}$ (potencial igual $\mathrm{a}+0,246 \mathrm{~V}$ à $\left.25^{\circ} \mathrm{C}\right)^{20}$. Já em 1906, o biólogo M. Z. Cremer (1865-1935), utilizando uma membrana de vidro, percebeu o aparecimento de um potencial entre duas soluções alcalinas ${ }^{4,5}$. Por fim, em 1909, Fritz Haber (1868-1934) e Z. Klemensiewicz (1874-1948) descobriram que o potencial na membrana de vidro era função da concentração dos íons hidrogênio ${ }^{4,5,44}$. 
Em 1921, E. Biilmann (1873-1946) introduziu o eletrodo de quinidrona (quinona/hidroquinona) ${ }^{14,31}$, muito utilizado na época. Ele mesmo defendeu sua proposta dessa forma: "O eletrodo de hidrogênio é tedioso de manipular e freqüentemente apresenta falhas na utilização. A platina precisa ser platinizada por eletrólise. Após isso o eletrodo precisa ser lavado e saturado com hidrogênio por eletrólise numa solução diluída de ácido sulfúrico. Além disso, o eletrodo só pode ser utilizado cerca de 20 vezes.(...) Todos esses problemas e perda de tempo e material podem ser eliminados pela utilização de um eletrodo de quinidrona, que é muito mais simples e também confiável" 21.

No eletrodo de quinidrona, ao invés de utilizar gás hidrogênio, um pouco de quinidrona era introduzida ao redor do eletrodo de platina (não era preciso platinizá-lo). O equilíbrio entre o hidrogênio e a quinidrona na solução era alcançado em curto período de tempo e a medida era constante. Apesar de seu excelente desempenho em meio ácido, o eletrodo de quinona/hidroquinona não funcionava bem em $\mathrm{pH}$ acima de 8 , pois era afetado por reações de consumo irreversíveis do reagente ${ }^{20,31}$.

Apesar de todos os esforços, inclusive no que tange à adoção de diversos formatos, os eletrodos apresentavam muitos problemas, especialmente a durabilidade e a inexatidão das medidas com o uso contínuo ${ }^{5,44-46}$. Esses problemas só foram solucionados em 1931, depois que Duncan A. McInnes (1885-1965) e Malcolm Dole (1903-1990) desenvolveram um vidro apropriado sensível ao íon hidrogênio ${ }^{46}$. Sua composição, utilizada até os dias atuais, é $\mathrm{SiO}_{2}$, $72 \% ; \mathrm{Na}_{2} \mathrm{O}, 22 \%$ e $\mathrm{CaO}, 6 \%$. Apesar de representar um notável avanço para o estabelecimento de medidas de $\mathrm{pH}$, o eletrodo de vidro também apresenta limitações ${ }^{6,12,13,35,43,46}$ : sua faixa ótima de operação situa-se entre pH 2 e 11. Acima de 11, ocorre o chamado "erro alcalino": a resposta não é mais linear ao pH. Abaixo de $\mathrm{pH}$ 2 (alta concentração do íon hidrogênio), superpõe-se o chamado "potencial de difusão", muito elevado devido à excepcional mobilidade iônica do $\mathrm{H}^{+}$, à força eletromotriz medida. Mesmo após cuidadosa calibração, a confiabilidade é prejudicada porque esse potencial de difusão varia consideravelmente com a concentração do íon hidrogênio em acidez muito elevada.

Os outros componentes de uma montagem eram: instrumento de zero - tinha o objetivo de constatar a presença ou a ausência de corrente no sistema elétrico. Para isso, empregava-se um galvanômetro, um eletrômetro capilar ou um microamperímetro ${ }^{15,16}$; caixa de resistência variável ou reostato - regulava a milivoltagem (miliamperagem) em função da variação da resistência propiciada pelo equipamento. Em geral, $1 \mathrm{Ohm}$ de resistência devia corresponder à queda de 1 milivolt no sistema e, acessórios - fios, interruptores e comutadores.

Por volta de 1930, além da confiabilidade problemática das montagens existentes, ainda não havia consenso sobre em que unidade seria expressa a medida experimental da acidez de uma solução (milivolts, miliamperes, Ohms) ) $^{3,20,35}$.

\section{A INVENÇÃO DO MEDIDOR DE pH (ACIDÍMETRO OU PEAGÂMETRO)}

Em 1930 Arnold O. Beckman ${ }^{44,47}$ (1900-2004), químico e engenheiro químico americano, foi contratado por uma agroindústria para desenvolver um método robusto e confiável de testar a acidez de frutas. Beckman, então, criou uma nova solução utilizando um tubo de vácuo amplificado integrado aos medidores e eletrodos que a agroindústria já empregava, dando origem ao primeiro aparelho medidor de acidez. Em 1934 surgia o primeiro bem-sucedido medidor de $\mathrm{pH}$ (Figura 1), sendo comercializado a partir do ano seguinte.

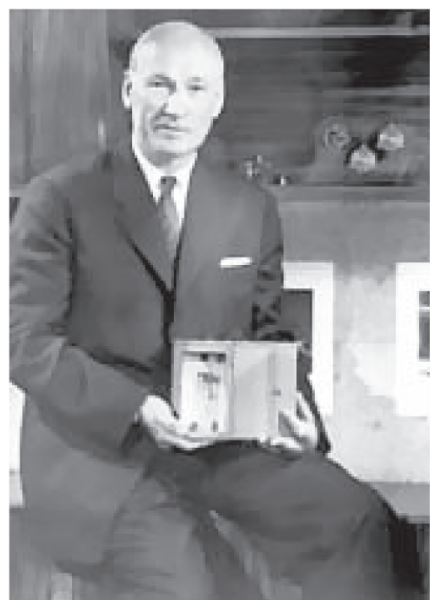

Figura 1. O primeiro peagâmetro comercial (1935), exibido pelo próprio Arnold Beckman. Cortesia de Beckman Coulter, Inc.

Isso só foi possível porque Beckman possuía um grande conhecimento de engenharia elétrica (componentes eletrônicos e tubos de vácuo), de modo que pôde integrar os componentes de seu aparelho, fato então inédito naquela época. Seu produto permitia o emprego do eletrodo de vidro, recém-inventado, o que significou um salto espetacular na obtenção de medidas rápidas e confiáveis da acidez $z^{11,48}$

Beckman percebeu o grande potencial de mercado que seu produto possuía ${ }^{44,47,48}$ e tentou oferecê-lo para várias indústrias, sem sucesso. Então resolveu criar sua própria empresa. Em 1935, fundou a "National Technical Laboratories", que comercializou o primeiro medidor de $\mathrm{pH}$, e que foi o começo da empresa que hoje é conhecida como "Beckman Instruments". Seu aparelho chamavase "acid-o-meter", daí os termos "acidimeter" e "acidímetro". Por conta da medida de $\mathrm{pH}$ que realiza, o termo "peagâmetro" se impôs mais tarde na língua portuguesa. Em 1935, uma segunda versão do instrumento foi lançada comercialmente, e a patente foi depositada no ano seguinte. As vendas de peagâmetros nos Estados Unidos saltaram de 444 unidades, em 1936, para quase 2000 unidades, três anos depois ${ }^{48}$.

Uma vantagem imediata deste aparelho era o tamanho menor frente às montagens então em voga; isso decorria da integração dos componentes em um único aparelho. Ele não funcionava a eletricidade, mas a bateria (chumbo-ácido, provavelmente), o que justificava o peso do aparelho em relação ao seu tamanho. Todavia, isso permitia que fosse transportado para o local onde era necessária a medida de $\mathrm{pH}$, o que era de valor especial nas áreas de geologia, agronomia, veterinária e na indústria química em geral.

Apesar de ser normalmente creditado a Beckman o lançamento do primeiro peagâmetro, deve-se registrar que em 1935 uma outra proposta desse aparelho foi lançada pela empresa dinamarquesa Radiometer ${ }^{45,49}$. O que a literatura indica claramente é que ambas as "descobertas" tiveram como inspiração o trabalho de L. W. Elder e W. H. Wright ${ }^{50}$, professores do Departamento de Química da Universidade de Illinois. Eles foram os primeiros a sugerir que as medidas de $\mathrm{pH}$ fossem realizadas com eletrodo de vidro e potenciômetro de tubo de vácuo, superando a montagem baseada na agregação de componentes isolados. Independente de quem ou qual foi a empresa que "inventou" o medidor de $\mathrm{pH}$, é importante enfatizar que foi a junção dos conceitos de química em solução aquosa ( $\mathrm{pH}$, tampões), eletroquímica (eletrodo) e eletrônica (medidor) que tornou possível a concretização do aparelho.

$\mathrm{O}$ advento do peagâmetro fez com que a dosagem de acidez por indicadores corados se restringisse a procedimentos de rotina 
bem estabelecidos, à área de ensino (iniciação às técnicas de dosagem), ou ainda a casos onde a precisão da medida não precisa ser rigorosa ${ }^{13,35,42}$.

\section{A evolução do peagâmetro}

Com o passar dos anos, foram introduzidas grandes melhorias nos medidores de $\mathrm{pH}$ até sua forma atual, incluindo eletrodos de vidro de alta estabilidade, controle por microprocessadores e visores digitais.

As Figuras 2 a 4 ilustram a evolução técnica do instrumento, visando dar a ele versatilidade e aplicabilidade crescentes.

O primeiro passo foi a eletrificação do aparelho, em contraste com as primeiras versões (que funcionavam à bateria) ${ }^{47}$. Mas esses modelos ainda eram muito limitados. No instrumento da década de 1950 (Figura 2), existe apenas um ajuste de escala pelo parafuso preto, realizado ao se colocar uma solução de $\mathrm{pH}$ rigorosamente 7,00; o desvio na escala era compensado pelo ajuste da posição do ponteiro por meio do parafuso. Já os modelos fabricados a partir do início dos anos 1960 apresentam uma variedade de recursos muito maior, com destaque para a introdução do circuito interno de compensação de temperatura, ponto que responde pela versatilidade do instrumento. A forma de apresentação do resultado passou a ser feita tanto em valores de $\mathrm{pH}$ como em milivoltagem; o mostrador evoluiu do modelo analógico (Figura 3) para o digital (Figura 4). $\mathrm{O}$ ajuste do zero passou a ter dois controles: ajuste grosso e fino. Os modelos atuais possuem menos de $50 \%$ do tamanho dos instrumentos da década de 1980. Além disso, uma originalidade é a ausência de botões para controle e ajuste dos parâmetros, mas comandos que são acionadas sob pressão.

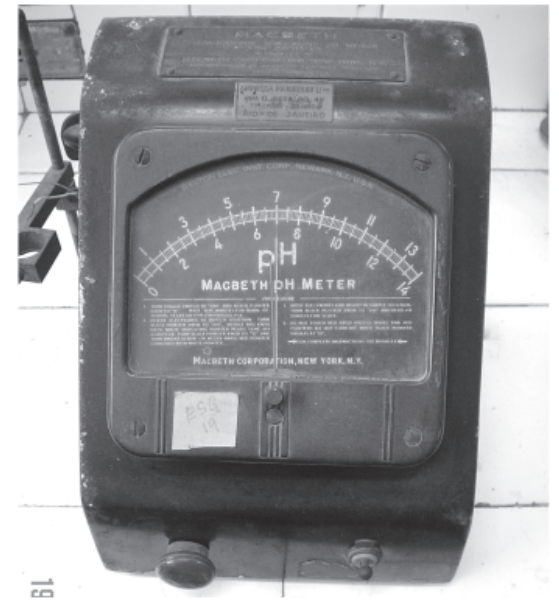

Figura 2. Peagâmetro de origem norte-americana, década de 1950. Seu visor apresenta duas escalas de pH alternadas: 1 a 13 (superior) e 2 a 14 (inferior). Dimensões: $24 \mathrm{~cm}$ de comprimento, $20 \mathrm{~cm}$ de largura e $16 \mathrm{~cm}$ de altura; $m=$ 1,6 kg. Acervo do Museu da Química Prof. Athos da Silveira Ramos

O princípio dos peagâmetros atuais é a determinação da força eletromotriz (f.e.m.) de uma célula eletroquímica constituída por uma solução cujo pH se deseja medir e dois eletrodos. Um deles é o eletrodo de referência, cujo potencial independe do $\mathrm{pH}$ da solução. O outro é o eletrodo indicador, o qual adquire um potencial dependente do $\mathrm{pH}$ da solução sob exame. O eletrodo de vidro é o modelo mais usado para as medidas de $\mathrm{pH}$.

A medição da f.e.m. de uma célula pode ser expressa por:

F.e.m. $=\left[\mathrm{E}_{\text {vidro }}-\mathrm{E}_{\text {referência }}\right]$

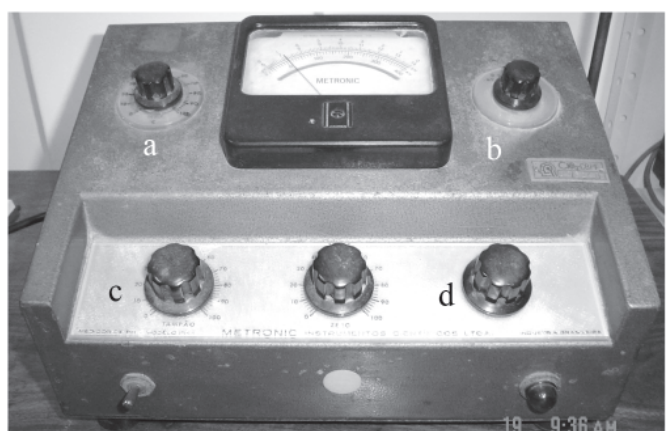

Figura 3. Primeiro modelo de peagâmetro construído no Brasil, 1964: (a) seletor de temperatura; (b) seletor de escala; (c) seletor de $\mathrm{pH}$ de tampão (calibração); (d) ajuste de zero (grosso/fino). O visor mostra escalas de $\mathrm{pH}$ e de milivoltagem. Dimensões: $30 \mathrm{~cm}$ de comprimento, $28 \mathrm{~cm}$ de largura e 20 cm de altura; $m=3,5 \mathrm{~kg}$. Acervo do Museu da Química Professor Athos da Silveira Ramos

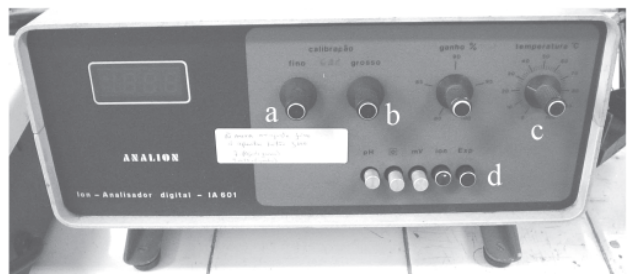

Figura 4. Peagâmetro digital, origem nacional, 1982, um dos primeiros modelos comerciais deste tipo: (a) ajuste de zero (grosso/fino); (b) ajuste de ganho; (c) seletor de temperatura; (d) seletores de escala. Dimensões: 36 $\mathrm{cm}$ de comprimento, $30 \mathrm{~cm}$ de largura e $20 \mathrm{~cm}$ de largura; $m=2,0 \mathrm{~kg}$

Na faixa de pH 2-11, a faixa ótima de operação, a dependência do potencial do eletrodo de vidro com o $\mathrm{pH}$ pode ser expressa segundo a Equação 7

$\mathrm{E}_{\text {vidro }}=\mathrm{E}_{\text {vidro }}^{\circ}-0,059 \mathrm{pH}$

onde $\mathrm{E}_{\text {vidro }}{ }^{0}$ é o potencial padrão do eletrodo de vidro. Esse valor varia para cada instrumento, dependendo também da conservação e do uso do eletrodo.

\section{CONCLUSÕES}

A necessidade de se determinar a acidez de um meio foi reconhecida muito antes de se estabelecerem metodologias experimentais confiáveis e reprodutíveis de dosagem. Desse modo, pode-se traçar a evolução da inserção da determinação da acidez na rotina do trabalho em Química e outras ciências correlatas, em vários estágios distintos: estabelecimento de fatos experimentais e dosagens colorimétricas em base empírica; proposição de teorias que explicassem os fenômenos observados e de concepções que levariam ao estabelecimento posterior do conceito de $\mathrm{pH}$; adoção de diversos modos de expressar a concentração do íon hidrogênio, particularmente aquela proposta por H. Friedenthal; a proposição da definição de $\mathrm{pH}$, por Sörensen e, o desenvolvimento de métodos eletrométricos, culminando com a invenção do peagâmetro, com o qual eram superadas as limitações dos métodos colorimétricos e as montagens complicadas e frágeis dos sistemas elétricos de então.

$\mathrm{O}$ conceito de $\mathrm{pH}$ adveio de uma situação muito própria dos pesquisadores que lidam com sistemas biológicos, mas esbarrou no ceticismo e no não reconhecimento imediato pelos químicos 
como um parâmetro de real utilidade para trabalhos de rotina. Essa situação mudou quando se reconheceu seu valor em procedimentos laboratoriais e industriais.

A invenção do peagâmetro é um claro exemplo de instrumento concebido para responder às deficiências e necessidades da ciência em geral, no afã de buscar medidas confiáveis de um parâmetro de grande aplicabilidade prática. Esse invento só foi possível ao se conjugar conhecimentos de diversas áreas que possibilitaram o grande salto que o viabilizou: a integração dos componentes, antes empregados isoladamente, em um único aparelho. Essa evolução prosseguiu ao longo do século $\mathrm{XX}$, com a adoção de novos recursos oferecidos pelo peagâmetro e a digitalização dos componentes (fenômeno observado na instrumentação em geral), o que levou à redução do tamanho do aparelho.

\section{AGRADECIMENTOS}

Aos Prof. C. A. L. Filgueiras, L. M. B. Gomes e N. P. dos Santos (IQ/UFRJ) pela análise crítica deste trabalho e pelas sugestões oferecidas.

\section{REFERÊNCIAS}

1. Martin Jr., K.; J. Chem. Educ. 1932, 9, 1010.

2. Terci, D. B. L.; Rossi, A. V.; Quim. Nova 2002, 25, 684.

3. Bates, R. G.; Treatise on Analytical Chemistry, Wiley-Interscience: Nova Iorque, 1978, vol. 1, p. 821.

4. Szabadváry, F.; J. Chem. Educ. 1964, 41, 285

5. Szabadváry, F.; J. Chem. Educ. 1964, 41, 105

6. Vogel, A. I.; Química Analítica Qualitativa, $5^{\text {a }}$ ed., Ed. Mestre Jou: São Paulo, 1981, p. 65-75.

7. Blasdale, W. C.; Principles of Quantitative Analysis - An Introductory Course, van Nostrand: Nova Iorque, 1918.

8. Pozzi-Escot, H.; Le pH-Force D’Acidité et D'Alcalinité, Dunod: Paris, 1930.

9. Bravo, G. A.; La Concentrazione Degli Ioni Idrogeno, Tipografia Sociale Torinese: Torino, 1929.

10. Friedenthal, H.; Z. Elektrochem. 1904, 10, 113.

11. Kolb, D.; J. Chem. Educ. 1979, 56, 49.

12. Mendham, J.; Denney, R. C.; Barnes, J. D.; Thomas, M. J. K.; Análise Inorgânica Quantitativa, 6⿳亠 ed., LTC: Rio de Janeiro, 2002, p. 167.

13. Galster, H.; pH Measurement (Fundamentals, Methods, Applications, Instrumentation), VCH: Weinheim, 1991, p.127.

14. Sulton, F.; Mitchell, A. D.; A Systematic Handbook of Volumetric Analysis, $12^{\mathrm{a}}$ ed, P. Blakiston's Son \& Co: Philadelphia, 1935.
15. Kopaczewski, W.; Les Ions D’Hydrogene, Gauthier-Villars et Cie: Paris, 1926.

16. Clark, W. M.; The Determination of Hydrogen Ions, van Darmstad: Baltimore, 1926.

17. Pontos de Chimica - Segundo os Programmas do Collegio Pedro II (ou Suplemento a Chimica de Basin) - Coleção FTD, Livraria Paulo de Azevedo e Cia: Rio de Janeiro, 1928, cap XV.

18. Pinto, P. A.; Noções Rudimentares de Química Analítica e Quantitativa, Livraria Francisco Alves: Rio de Janeiro, 1932.

19. Blasdale, W. C.; The Fundamentals of Quantitative Analysis, van Nostrand: Nova Iorque, 1928.

20. Britton, H. T.; Hydrogen Ions: The Determination and Importance in Pure and Industrial Chemistry, van Nostrand: Nova Iorque, 1932.

21. Biilmann, E.; Ann. Chim. Phys. 1921, 15, 109.

22. Boll, M.; Leroide, J.; Précis d'Analyse Chimique, Dunod: Paris, 1927.

23. Crane Jr., F. E.; J. Chem. Educ. 1961, 38, 365.

24. Blackaddor, T.; J. Am. Leather Chem. Assoc. 1924, 19, 650.

25. Guillaumin, C. O.; Bull. Soc. Chim. Biol. 1926, 8, 160.

26. Wherry, E. T.; Bull Wagner Free Inst. Sci. 1927, 2, 59.

27. Giribaldo, F.; Biochem. Z. 1925, 163, 8.

28. Giribaldo, F.; F. Bull. Soc. Chim. Biol. 1925, 7, 652.

29. Clark, W. M.; J. Wash. Acad. Sci. 1921, 11, 199.

30. Kolthoff, I. M.; Biochem. Z. 1926, 169, 490.

31. Chakmakjiam, A. H.; J. Chem. Educ. 1929, 6, 1659.

32. Chagas, A. P.; Quim. Nova 2000, 23, 126.

33. Kintner, R. C.; Collected Papers on the Teaching of Chemical Engineering, The American Institute of Chemical Engineers: Nova Iorque, 1940.

34. Pratolongo, V.; Principii de Acidimetria Applicata, Hoelpi: Milão, 1931.

35. Kolthoff, I. M.; Sandell, E. B.; Textbook of Quantitative Inorganic Analysis, The MacMillan Company: Nova Iorque, 1947.

36. Kolthoff, I. M.; Concentration et Ions Hydrogène, Gauthier-Villars: Paris, 1925.

37. Lubs, H. A.; Clark, W. M.; J. Wash. Acad. Sci. 1916, 6, 481.

38. Ashley, R. H.; J. Chem. Educ. 1928, 5, 1647.

39. Quintella, D. M.; Revista Syniatrica 1941, 34, 181.

40. Da Antiga Farmácia do Anjo à Grande Empresa Químico-Farmacêutica, Merck: Darmstadt, 1968.

41. Scott, W. W.; Standard Methods of Chemical Analysis, $5^{\text {th }}$ ed., Van Nostrand: Nova Iorque, 1939, vol. I.

42. Fales, H. A.; Kenny, F.; Inorganic Qualitative Analysis, D. AppletonCentury: Nova Iorque, 1943.

43. Harris, D.; Análise Química Quantitativa, 5ª ed., LTC: Rio de Janeiro, 2001, p. 334.

44. Tarbell, D. S.; Tarbell, A. T.; J. Chem. Educ. 1980, 57, 133.

45. Ruzicka, J.; J. Chem. Educ. 1997, 74, 167.

46. Dole, M.; J. Chem. Educ. 1980, 57, 134.

47. http://www.beckman-foundation.com, acessada em Julho 2004

48. Wotiz, J. H.; J. Chem. Educ. 1980, 57, 133.

49. Fernandes, J. C. B.; Kubota, L. T.; Quim. Nova 2001, 24, 120.

50. Elder, L. W.; Wright, W. H.; Proc. Natl. Acad. Sci. U.S.A. 1928, 14, 936. 